\title{
Evaluation of the Levels of phthalate Ester Plasticizers in Surface Water of Ethiope River System, Delta State, Nigeria
}

\section{EDJERE, O; ${ }^{*}{ }^{1}$ ASIBOR, IG; OTOLO, SE}

\author{
Department of Environmental Management and Toxicology, \\ College of Science, Federal University of Petroleum Resources, \\ P.M.B. 1221, Effurun, Delta State, Nigeria. \\ *Corresponding Author, email: asibor.godwin@fupre.edu.ng; tel: +234-8078350554
}

\begin{abstract}
The objective of this study was to determine the level of phthalate ester plasticizers in Ethiope River water samples. Gas chromatography (GC) coupled with mass spectrometer (MS) was used to evaluate the levels of dimethyl phthalate (DMP), diethyl phthalate (DEP), dibuthyl phthalate (DBP), diethylhexyl phthalate (DEHP), buthylbenzyl phthalate (BBP), di-n-octyl phthalate (DnOP in the water samples. Range of total phthalate level in different locations fell between $0.74 \mu \mathrm{g} / \mathrm{L}$ and $1.75 \mu \mathrm{g} / \mathrm{L}$. It was found that Sapele- 1 and Sapele-2 had highest total phthalates concentrations. The highest concentrations of phthalates were DBP and DEHP, which is consistent with their common use in plastic materials and other industrial chemicals. It was found that the individual phthalates concentration was low but total phthalate levels were high in most stations. The results for phthalates in the water samples is low but there is the need to guide against an upward rise in the concentrations as these may pose grave environmental and health concern for people living downstream of the river. These results can be used as reference levels for future monitoring programs for pollution studies of the river. (C) JASEM
\end{abstract}

http://dx.doi.org/10.4314/jasem.v20i3.15

Key words: phthalates, acid esters, plasticizers, Ethiope River, surface water, pollution

Most of the consumer products in our homes consist of additives known as ester plasticizers. They are group of synthetic compounds which are added to products in order to enhance flexibility and durability of the product (Schettler, 2006; Daiem, 2012).Phthalate ester plasticizers provide an array of benefits required for the many applications such as tubing and hose products,personal care products, household furnishing, building materials, children's toys, medical devices, flooring, wall-coverings, seals and gaskets, belts, wire and cable, and print rolls (Gao et al., 2014; Wang et al., 2015). More than three million metric tonnes of phthalates are produced annually. Phthalate plasticizers are not chemically bound to materials; they can leach at a constant rate from plastic products to the environment and consequently, are distributed in the ecosystem and have been described as the most abundant man-made environmental pollutant (Latini2005; Vitali et al., 1997; Zhang et al., 2015). They found ubiquitously in the environment as primarily diethylhexyl phthalate (DEHP), dibutyl phthalate (DBP) and in much lower concentrations dimethyl phthalate (DMP), diethyl phthalate (DEP), and Butylbenzyl phthalate (BBzP or $\mathrm{BBP}$, di-n-octyl phthalate (DnOP), diisononyl phthalate (DINP)

Humans are exposed to phthalate mainly via ingestion, inhalation and dermal exposure (Adibi et al., 2003). Phthalate are becoming a great environmental concern because of their ubiquitous nature and studies have indicated various reproductive toxicities and carcinogenic potentials. Phthalates are now known to cause a broad range of birth defects and lifelong reproductive impairment in laboratory animals exposed in-utero (Ema et al., 1998; Wine et al., 1997; Gray et al., 1999).

Phthalates have been found virtually in all compartments of the environment including fresh water (Tan 1995; Selyarai et al., 2015; DominguezMorueco et al., 2014; Liu et al., 2015; Liu et al., 2014; Gao and Wen 2016), lake sediments, buried PVC, landfill leachates, atmospheric aerosols (Simoneitet al., 1988), in rain water (Simoneit and Mazurek, 1989). Reports showed that, in river water DEHP, DBP, diisobutyl phthalate (DIBP) and DEP were found in all samples, with DEHP as the dominant compound with concentrations of up to 10 $\mu \mathrm{g} / \mathrm{l}$ and a mean value of $1 \mu \mathrm{g} / \mathrm{l}$ for the River Rhine(Furtmann 1994).

Majority of the communities in river metropolis ignorantly dump these consumer products containing phthalate ester plasticizers into the river system thereby posing risk to the aquatic habitat as well as the humans who source their water from the river. Adewuyi (2012) investigated the identity and estimated the phthalates concentration in supposed treated medical wastes from a hospital sewer and water from a receiving river in Ibadan city, Nigeria. High levels of the phthalate esters were found in the treatment effluent samples from the sewage plant and the samples from the receiving river. Olujimi et al., 
(2014) studied occurrence and concentration of phthalate esters in river sediment around the oxidation ponds at Covenant University in Nigeria and confirms that sediment samples act as a "storage" or "reservoir" for phthalates. A study on Phthalates and other plastic additives in Surface sediments of the Cross River System in Nigeria showed that primary sources of these phthalates were considered to be the result of direct discharge of untreated effluent/solid waste and emissions arising from burning of refuse containing plastic materials, respectively (Oyo-Ita et al., 2014).

Due to the environmental and health risk posed by these synthetic compounds, their importance in Nigerian rivers should not be underestimated. Hence, the purpose of this study is to determine and report some of the phthalates present in Ethiope River system.

\section{MATERIALS AND METHODS}

Area of Study: River Ethiope, reputed to be one of the deepest inland waterways in Africa, is known for its natural clean/ deep watersource. Its source is at the foot of a giant silk-cotton tree at Umuaja in Ukwuani Local Government Area of Delta state (Enamuotor, 2013). The river is located in the western part of Delta State and flows towards to the eastern part. It is situated between latitude $5.53^{\circ}$ and $6.05^{\circ}$ North and longitude $5.30^{\circ}$ and $6.05^{\circ}$ East. It covers a distance of 96.6 kilometres and flows into the Atlantic Ocean through the Benin River. The River lies within the humid tropical zone with defined dry season (November - March) and rainy season (April October).

The river serves as a major source of water for drinking, bathing, fishing, washing, and recreation for the people of Umuaja, Umutu, Obiaruku, Abraka, Eku, Igun, Sapele and some other small communities in Delta State, Nigeria. The communities, through which the River traverses, are mainly peasant farmers whose products include food stuff such as yams, corn, vegetables, cassava, plantain and fruits. Agricultural activities in the area are mostly carried out along the bank of the River, and agricultural wastes (domestic wastes, livestock manure, fertilizers, pesticides, etc) are discharged directly into the river or entrained in runoff into the river after rainfall. Some physicochemical characteristics of Ethiope River have been reported (Aluyi et al., 2003; Enamuotor, 2013).

Sample Collection: Water samples were collected from eight points along the river channel in a glass bottle and stored in an ice chest until arrival in the laboratory, where they were kept in fridge.

Chemicals and materials: Anhydrous sodium sulphate oven heated at $400^{\circ} \mathrm{C}$; cyclohexane distillated in an all glassware;acetone; 1,11Dibromoundecane (ISTD); reagent water; Agilent gas chromatograph 6890N, coupled with MS; Sample collection bottles; 11 Erlenmeyer flasks; glass coated metal magnetic mixer; Upward delivery glass separating funnel; $10 \mathrm{ml}$ vials with septum seals (Silicon/PTFE); Balance (3 decimal places); glass beakers; spatulas; forceps; aluminium foil; solvent reservoir bottle; calibrated syringe; ultrasonic bath; bunsen burner; drying oven; muffle furnace; desiccators; measuring cylinders; test tubes; pasteur pipettes; calibrated pipette.

Sample Handling and pre-treatment: Water samples were collected in amber glass containers. Conventional sampling practices were followed. No special sample preservations and storage steps were taken since phthalate are stable at $\mathrm{pH}$ 7.Samples were collected and sealed with a glass stopper followed by a metal clip. The samples were refrigerated at $4^{\circ} \mathrm{C}$ free from light from the time of collection until extraction.

Extraction of Water Sample: A subsample of 1L was weighed into a calibrated Erlenmeyer flask of 1L. To this is added $1 \mathrm{ml}$ Cyclohexane internal Standard solution and then $9 \mathrm{ml}$ Cyclohexane. With the aid of a glass coated magnet the sample was then liquid / liquid intensively extracted for a minimum of an hour. Using an upward delivery glass separating funnel, the solvent Extract was then isolated in a 10 $\mathrm{ml}$ vial. Sample volume is $1 \mathrm{~L}$ in $10 \mathrm{ml}$ Cyclohexane Extract.

Analysis of Phthalate in water using GC/MS: The analytes in the extract were separated by means of capillary gas chromatography using temperature programming. The chromatographically separated phthalate esters were detected and measured with Mass Spectrometer. This process is made possible by large volume injection (LVI) technique used to introduce $10 \mu \mathrm{l}$ of the sample solvent extract at a rate of approx. $4.6 \mu \mathrm{l} / \mathrm{sec}$ into the injector. The injector is kept at an initial temperature of $78^{\circ} \mathrm{C}$ and rises gradually at the rate of $5^{\circ} \mathrm{C} / \mathrm{sec}$ to $300^{\circ} \mathrm{C}$ so as to enable complete volatilisation of solvent into the analytical column. Oven initial temperature was kept at $70^{\circ} \mathrm{C}$ and on injection rises to $300^{\circ} \mathrm{C}$ at a rate of $20^{\circ} \mathrm{C} / \mathrm{min}$. Injector's temperature is brought back quickly to normal by the use of a liquid Nitrogen cryo cooling unit. The new method for analysis of Phthalate in water samples using GC/MS was validated according to Skoog et al. (1998), Edjere (2006) and Institute Bachema AG Quality Management Guidelines as certified by ISO 17025 (Institute Bachema, 2006).

Data Analysis: All the statistical analyses were carried out using the Paleontological Statistics (Hammer et al., 2003) and SPSS16.0. A one-way analysis of variance (ANOVA) at a confident level of 0.05 was used to assess if phthalate levels varied 
significantly among sampling stations. The Duncan Multiple Range Test was used to conduct the post hoc comparisons between pairs of treatments based on comparing the range of a subset of the sample means at the confident level ( $\mathrm{P}$ at 0.05 ). The population means could be considered significantly different if the mean difference of the subset exceeds the confident level $(\mathrm{p}>0.05)$. Once a range is found not to be significant, no further subsets of this group are tested.

\section{RESULTS AND DISCUSSION}

Table 1: Concentrations of different Phthalates in different water samples ( $\mu \mathrm{g} / \mathrm{L})$

\begin{tabular}{lllllllll}
\hline Station & Description & \multicolumn{1}{c}{ DMP } & DEP & DBP & BBP & DEHP & DnOP & TOTAL \\
\cline { 3 - 8 } $\mathbf{1}$ & & ND & $0.11 \pm 0.02$ & $0.64 \pm 0.01$ & ND & $0.34 \pm 0.00$ & $0.05 \pm 0.01$ & $1.14 \pm 0.03$ \\
$\mathbf{2}$ & Umutu-1 & ND & $0.19 \pm 0.01$ & $0.44 \pm 0.00$ & ND & $0.42 \pm 0.00$ & $0.03 \pm 0.01$ & $1.08 \pm 0.02$ \\
$\mathbf{3}$ & Abraka-1 & ND & $0.13 \pm 0.00$ & $0.62 \pm 0.00$ & ND & $0.52 \pm 0.00$ & $0.02 \pm 0.00$ & $1.29 \pm 0.00$ \\
$\mathbf{4}$ & Abraka-2 & ND & $0.09 \pm 0.00$ & $0.20 \pm 0.00$ & ND & $0.40 \pm 0.00$ & $0.02 \pm 0.00$ & $0.71 \pm 0.00$ \\
$\mathbf{5}$ & Eku-1 & ND & $0.18 \pm 0.01$ & $0.84 \pm 0.00$ & ND & $0.54 \pm 0.03$ & $0.05 \pm 0.02$ & $1.61 \pm 0.06$ \\
$\mathbf{6}$ & Eku-2 & ND & $0.18 \pm 0.00$ & $0.16 \pm 0.01$ & ND & $0.40 \pm 0.00$ & ND & $0.74 \pm 0.01$ \\
$\mathbf{7}$ & Sapele-1 & ND & $0.17 \pm 0.02$ & $1.02 \pm 0.00$ & ND & $0.53 \pm 0.01$ & $0.03 \pm 0.01$ & $1.75 \pm 0.04$ \\
$\mathbf{8}$ & Sapele-2 & ND & $0.19 \pm 0.01$ & $0.94 \pm 0.00$ & ND & $0.46 \pm 0.00$ & $0.03 \pm 0.01$ & $1.62 \pm 0.02$ \\
Min & & 0.00 & 0.09 & 0.16 & 0.00 & 0.34 & 0.00 & 0.71 \\
Max & & 0.00 & 0.19 & 1.02 & 0.00 & 0.54 & 0.05 & 1.75 \\
Mean & & 0.00 & 0.16 & 0.61 & 0.00 & 0.45 & 0.03 & 1.2425 \\
s.d. & & 0.00 & 0.0338 & 0.2556 & 0.00 & 0.0613 & 0.0098 & 0.325 \\
\hline
\end{tabular}

ND: Not detected

The study showed that DBP concentrations were found to have the highest average $(0.61 \mu \mathrm{g} / \mathrm{L})$ contribution in the river followed by DEHP and DEP with mean concentrations of $0.45 \mu \mathrm{g} / \mathrm{L}$ and $0.16 \mu \mathrm{g} / \mathrm{L}$ respectively, while DMP, BBP and DnOP were found in low concentrations. The fact that DBP, DEHP and DEP were the highest contributor to the phthalates concentrations is because they are the most extensively used in manufacturing processes and therefore the most commonly found phthalate in the manufactured products (Kimber and Dearman, 2010). Most detailed toxicological studies have centred primarily on DEHP and DBP as they account for a greater percentage of the phthalates, which are used commercially (USEPA, 1989; US ATSDR, 2002). Research works done on DEHP and DBP has confirmed that they elicit the most toxicity to terrestrial organisms, fish and aquatic invertebrates (EC, 2008,; Staples et al. 1997). Ecotoxicity studies with these phthalates also showed adverse effects to aquatic organisms with a broad range of endpoints web.
Results of data collected are presented in Tables 1, 2, 3 and 4 and Figure 1 respectively. DMP and BBP phthalates were not detected in all the water samples, while concentration for DEP, DBP and DEHP in different sample locations ranges from $0.09-0.19 \mu \mathrm{g} / \mathrm{L}$ $(0.61 \pm 0.034) ; 0.20-1.02 \mu \mathrm{g} / \mathrm{L}(0.61 \pm 0.256)$ and $0.34-$ $0.54 \mu \mathrm{g} / \mathrm{L}(0.45 \pm 0.061)$. The concentrations of DnOP were in the range of $0.00-0.05 \mu \mathrm{g} / \mathrm{L}(0.03 \pm 0.010)$ except for location at Eku-2 in which phthalates were not detected (Table 1). and at concentrations that coincide with measured environmental concentrations. Toxic effects were observed at environmentally relevant exposures in the low $\mathrm{ng} / \mathrm{L}$ to $\mu \mathrm{g} / \mathrm{L}$ range (Oehlmann et al. 2008).DMP and BBP were below detection limits in all the locations. This may be as a result of their regulation in manufacturing processes (Kamrin, 2009; Kavlock et al., 2002; Edjere et al., 2015).

The average amount of DEP found in the sampling locations was $0.16 \mu \mathrm{g} / \mathrm{L}$. Although, the value in this report is low compared to some other work, a study by the National Toxicology Program showed that DEP can damage the male reproductive system of animals in the womb, reduce sperm concentrations at the highest DEP dose and can also lead to abnormally large prostate glands (Lamb et al., 1997). Therefore, there is the need to control the leachates of this phthalates into the aquatic medium where they may lead to contaminate the food aquatic food

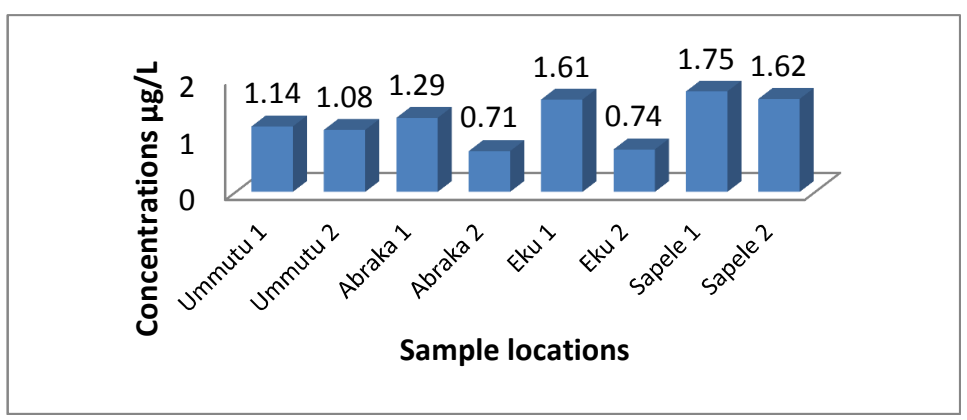

EDJERE, O; ASIBOR, IG; OTOLO, SE 
Fig 1: Total concentration values of phthalate in different sample locations

The trend of total concentration values in sample locations from lowest to the highest is as indicated in Figure 1. Highest concentration of phthalates was recorded in Station 7 (Sapele-1) with a value of $1.75 \mu \mathrm{g} / \mathrm{L}$; followed by Stations 8 and 5 with concentrations of $1.62 \mu \mathrm{g} / \mathrm{L}$ and $1.61 \mu \mathrm{g} / \mathrm{L}$ respectively. The lowest concentrations of phthalates were recorded in Stations 4, 6 and 2 with values of $0.71 \mu \mathrm{g} / \mathrm{L}, \quad 0.74 \mu \mathrm{g} / \mathrm{L}$ and $1.08 \mu \mathrm{g} / \mathrm{L}$. The high phthalates concentrations recorded in Stations 7 and 8 (Sapele-1 and 2) may be attributed to the high industrial and commercial activities taking place in this area coupled with the burning of refuse which are later washed down the channels of the river.

The results were subjected to a one-way analysis of variance (ANOVA) at a confident level of 0.05 to assess if phthalate levels varied significantly between sampling stations. All statistical analysis was performed with SPSS16.0. The statistical analysis showed that there was significant variation in phthalate levels for DEHP, DBP, and DnOP in the stations $(\mathrm{p}<0.05)$ while DEP showed no significant difference $(p>0.05)$ as shown in Tables 2, 3 and 4.

Table 2: Duncan Multiple Range Test for DBP

\begin{tabular}{cccccr}
\hline Station & $\begin{array}{l}\text { No. } \\
\text { Replicates }\end{array}$ & of & \multicolumn{4}{c}{ Subset for alpha = 0.05 } \\
\cline { 3 - 6 } 6 & 3 & $\mathrm{~A}$ & $\mathrm{~B}$ & $\mathrm{C}$ & $\mathrm{D}$ \\
4 & 3 & 0.1600 & & \\
2 & 3 & 0.2000 & & \\
3 & 3 & & 0.4400 & \\
1 & 3 & & 0.6200 & 0.6200 & \\
8 & 3 & 0.6400 & 0.6400 & \\
5 & 3 & & & 0.7400 & 0.8400 \\
7 & 3 & & & 0.8400 & 1.0200 \\
Sig. & & 0.694 & 0.075 & 0.059 & 0.091 \\
Means for groups in homogeneous subsets are displayed
\end{tabular}

Table 3: Duncan Multiple Range Test for DEHP

\begin{tabular}{ccccc}
\hline Station & No. of Replicates & \multicolumn{3}{c}{ Subset for alpha $=0.05$} \\
\cline { 2 - 4 } 1 & 3 & $\mathrm{~A}$ & $\mathrm{~B}$ & $\mathrm{C}$ \\
4 & 3 & 0.3400 & 0.4000 & \\
6 & 3 & 0.4000 & 0.4000 & \\
2 & 3 & 0.4000 & 0.4200 & 0.5200 \\
3 & 3 & 0.4200 & 0.5200 & 0.5333 \\
7 & 3 & 0.5200 & 0.5333 & 0.5400 \\
5 & 3 & & 0.5400 & 0.6200 \\
8 & 3 & & 0.137 & 0.267 \\
Sig. & & & \\
\hline
\end{tabular}

From Tables 2, 3 and 4, stations in the same subset are significantly different from stations in other subsets. Also, stations in the same subset imply that they have close values of mean. Therefore, Stations 2 and 3 (Umutu-2 and Abraka-1) have close mean. This affinity was also displayed between Stations 4 and 6 (Abraka-2 and Eku-2) and Stations 5 and 7 (Eku-1 and Sapele-2). This is an indication of similar commercial and domestic activities in those areas.

Available data for plastic esters indicate that acute and chronic toxicity to fresh water aquatic life occur at concentration as low as $3 \mu \mathrm{g} / \mathrm{L}$, and would occur at lower concentrations for more sensitive species (USEPA, 1989).In this limited survey, DBP and
DEHP stand out as chemicals of concern, having the highest mean concentrations $(0.61 \mu \mathrm{g} / \mathrm{L}$ and $0.45 \mu \mathrm{g} / \mathrm{L}$ ) and because of the combination of their prevalence in products. The concentration at which they are found in both cosmetics, other products and in people's bodies, and their links to birth defects in laboratory studies is obvious(OSHA, 2009). Therefore, there is need to sensitise the populace of the potential threat of these products and the need to continually dispose of waste in an environmentally friendly manners, using the proper channel rather than using the river system as a cheap means of disposing wastes. 
Table 4: Duncan Multiple Range Test for DnOP

\begin{tabular}{ccccc}
\hline Station & No. of Replicates & \multicolumn{3}{c}{ Subset for alpha =0.05 } \\
\cline { 2 - 4 } 6 & 3 & $\mathrm{~A}$ & $\mathrm{~B}$ & $\mathrm{C}$ \\
3 & 3 & 0.0000 & 0.0200 & \\
4 & 3 & 0.0200 & 0.0200 & 0.0333 \\
2 & 3 & 0.0200 & 0.0333 & 0.0333 \\
7 & 3 & 0.0333 & 0.0333 \\
8 & 3 & 0.0333 & 0.0467 \\
5 & 3 & & 0.0533 \\
1 & 3 & & 0.072 \\
Sig. & & & \\
\hline
\end{tabular}

It is the opinion of the authors that government as well as policy formulators and implementers should provide sustainable measures for waste disposal instead of allowing the masses to ruin the river ecosystems and put the populace into health risks associated with water borne phthalates. Manufacturers should base their new safety assessment of phthalates in different products on recent scientific findings and consider aggregate doses and cumulative effects from exposures to multiple phthalates with common mechanisms and health endpoints. Companies should publicly pledge to voluntarily remove phthalates from their products and use other alternative in place of phthalates. Manufacturers should also indicate clearly all phthalate-containing products on their label that can be read easily before purchase.

Acknowledgement: The authors will like to thank Bachema Analytical Laboratories, Switzerland for creating an enabling environment for the analysis of the samples.

\section{REFERENCE}

Adewuyi, GO (2012).High Performance Liquid Chromatographic Identification and Estimation of Phthalates in Sewer Waste and a Receiving River in Ibadan City, Southwestern Nigeria. Journal of Water Resource and Protection, 4: 851-858.

Adibi, JJ; Perera, FP; Jedrychowski, W (2003). Prenatal exposures to phthalates among women in New York City and Krakow, Poland.Environ. Health Perspect. 111:1719-1722.

Aluyi, HSA; Atuanya, EI; Amoforitse, SC (2003). Bacteriological and physico-chemical investigations of Ethiope River, Delta State, Nigeria.African Journal of Applied Zoology and Environmental Biology. 5: 29-36.

EC(2008). European Union Risk Assessment Report Bis(2-Ethylhexyl) Phthalate (DEHP),CAS-No. 117-81-7. 1:80-85. EU R 23384 EN; Office for Official Publications of the European Communities:Luxembourg.
Daiem, MMA; Rivera-Utrilla, J; Ocampo-Perez, R; Mendez-Diaz, JD; Sanchez-Polo, M (2012). Environmental impact of phthalic acid esters and their removal from water and sediments by different technologies - a review. Journal of Environmental Management. 109: 164-178.

Dominguez-Morueco, N; Gonzalez-Alonso, S; Valcarcel, Y (2014). Phthalate occurrence in rivers and tap water from central Spain. Sci. Total Environ.501:139-46.

Edjere, O (2006). Trace determination of phthalates in groundwater samples by GC-MS using specific sample concentration techniques. M.Sc. Thesis, Dept. of Environmental Chemistry, Robert Gordon University, Aberdeen, Scotland.

Edjere, O; Asibor, IG; Otolo, SE (2015). Phthalate ester plasticizers in OrogodoRiver, Delta State and their potential health effects. International Journal of Environment and Pollution Research..3 (45): 1 - 8.

Ema, M; Miyawaki, E; Kawashima, K (1998). Further evaluation of developmental toxicity of di-n-butyl phthalate following administration during late pregnancy in rats. Toxicol Lett: 8: 8793.

Enamuotor, BO (2013). Assessment of Water Supply Potential of the River Ethiope, J. of Science and Multidisciplinary Research. 5(1): 84-99.

Furtmann, K (1994), Phthalates in surface water - a method for routine trace level analysis., Fres. $J$. Anal. Chem. 348: 291-296.

Gao DW, Li Z, Wen ZD, Ren NQ (2014). Occurrence and fate of phthalate esters in full-scale domestic wastewater treatment plants and their impact on receiving waters along the Songhua River in China. Chemosphere 95:24-32.

Gao, DW; Wen, ZD (2016). Phthalate esters in the environment: A critical review of their occurrence, biodegradation, and removal during 
wastewater treatment processes. Sci. Total Environ. 541:986-1001.

Gray, LE Jr; Wolf, C; Lambright, C; Mann, P; Price, M; Cooper, RL; Ostby, J (1999). Administration of potentially anti-androgenic pesticides (procymidone, linuron, iprodione, chlozolinate, p,p'-DDEand ketoconazole and toxic substance (dibutyl- and diethylhexylphthalate, PCB 169, and ethane dimethanesulphonate) during sexual differentiation produces diverse profiles of reproductive malformations in the male rat. Toxicol Ind Health. 15:94-118.

Hammer, O; Harper, DAT; Ryan, PD (2003). Palaeontological Statistics version 1.15.Kluwer Academic Publishers.

Institute Bachema AG (2006). Analytical laboratories Safety Manual materials and chemicals. LIMSOPHY-Laboratory Information and Management System. ISO-17025 Certified 2006.

Kamrin, MA(2009). Phthalate risks, phthalate regulation, and public health: a review. Journal of Toxicology and Environmental Health, Part B. 12:157-174.

Kavlock, R; Boekelheide, K; Chapin, R; Cunningham, M; Faustman, E; Foster, P; Golub, M; Henderson, R; Hinberg, I; Little, R; Seed, J; Shea, K; Tabacova, S; Tyl, R; Williams, P; Zacharewski, T (2002). NTP Center for the Evaluation of Risks to Human Reproduction: Phthalates expert panel report on the reproductive and developmental toxicity of di-nbutyl phthalate. Reprod. Toxicol. 16:489-527.

Kimber,I; Dearman, R (2010).An assessment of the ability of phthalates to influence immune andallergic responses.Toxicology. 271:73-82.

Lamb, J; Reel, J; Lawton, AD (1997). Diethylphthalate. NationalToxicology Program. Environmental Health Perspectives. 105: 45-62.

Latini, G (2005). Monitoring phthlalte exposure in humans.ClinicaChimicaActa.361:20-29.

Liu, X; Shi, J; Bo, T; Zhang, H; Wu, W; Chen, Q; Zhan, X (2014). Occurrence of phthalic acid esters in source waters: a nationwide survey in China during the period of 2009-2012. Environ. Pollut. 184:262-270.

Liu, X; Shi, J; Bo, T; Li, H; Crittenden, JC (2015). Occurrence and risk assessment of selected phthalates in drinking water from waterworks in China. Environ. Sci. Pollut. Res. Int. 22(14):10690-10698.
Oehlmann, J; Schulte-Oehlmann, U; Werner, K; Jagnytsch, O; Lutz, I; Kresten, K; Wollenberger, L; Santos, EM; Paull, GC; Van Look, KJW; Tyler, CR (2008). A Critical Analysis of the Biological Impacts of Plasticizers on Wild life. Philos. Trans. R. Soc., B: Biol. Sci. 364(1526): $2047-2058$.

Olujimi, OO; Aroyeun, OA; Akinhanmi, TF; Arowolo, TA (2014). Occurrence and Concentration of Phthalate Esters in River Sediment Around Covenant Oxidation Ponds, Covenant University, Ota, Ogun State. International Journal of Environment and Sustainability. 3 (2): 1-7.

OSHA (2009). Occupational Safety and Health Guideline for Dibutyl Phthalate. http ://www.osha.gov /SLTC/health guide lines/dibutyl phthalate/recognition.html

Oyo-Ita, OE; Ekpo, BO; Oyo-Ita, OI;Offem, JO(2014).Environment and Pollution. 3 (1): 6072.

Selyarai, KK; Sundaramoorthy, G; Ravichandran, PK; Girian, GK; Sampath, S; Ramaswamy, BR (2015).Phthalate esters in water and sediments of the Kaveri River, India: environmental levels and ecotoxicological evaluations. Environ. Geochem. Health.37(1):83-96.

Schettler, T (2006).Human exposure to phthalate via consumer products. Int J Androl 29:134-139.

Simoneit, BRT; Standley, LJ; Cox, RE (1988). Organic matter in the troposphere IV: lipids in harmattan aerosols of Nigeria Atmospheric.Environment. 22: 983-1004.

Simoneit, BRT;Mazurek, MA (1989).Organic tracers in ambient aerosols and rainwater. Aerosol Science \& Technology. 10: 267-291.

Skoog, DA; Holler, FA; Nieman, TA (1998).Principles of Instrumental Analysis. $5^{\text {th }}$ ed. Thompson Learning Academic Resource Center, United States.

Staples, CA; Adams, WJ; Parkerton, TF; Gorsuch, JW; Biggingers, GR; Reiner, KH (1997). AquaticToxicity of Eighteen Phthalate Esters.Environ. Toxicol. Chem., 16 (5): 875-891

Tan, GH (1995). Residue levels of phthalate esters in water and sediment samples from the Klang River basin, Bull. Environ. Contam.Toxicol. 54: 171-176. 
U.S. Agency for Toxic Substances and Disease Registry (ATSDR). 2002. Toxicological Profile for $\mathrm{Di}(2$-Ethylhexyl)phthalate (DEHP). http://www.atsdr.cdc.gov/toxprofiles/tp9.html.

USEPA (1989). Health and environmental effects profile for phthalicacid esters. Cincinnati, $\mathrm{OH}$, US Environmental Protection Agency,Office of Research and Development, Environmental Criteria andAssessment Office (EPA/600/22).

Vitali M, Guidotti M, Macilenti G, Cremisini C (1997). Phthalate esters in freshwaters as markers of contamination sources-a site study in Italy. Environment International. 23: 337-347.

Wang M, Yang XD, Bi WT (2015) Application of magnetic graphitic carbon nitride nanocomposites for the solid-phase extraction of phthalate esters in water samples. Journal of Separation Science. 38:445-452.

Wine, R; Li, LH; Barnes LH; Gulati, DK; Chapin, RE (1997).Reproductive toxicity of di-n-butyl phthalate in a continuous breeding protocol in Sprague-Dawley rats.Environ HealthPerspect. 105:102-107.

Zhang Y, Wang PJ, Wang L, Sun GQ, Zhao JY, Zhang, H (2015). The influence of facility agriculture production on phthalate esters distribution in black soils of northeast China. Science of the Total Environment. 506: 118-125. 